\title{
Rough Kansei Mining Model for Market-Oriented Product Design
}

\author{
Esra Akgül, ${ }^{1}$ Mihrimah Özmen, ${ }^{2}$ Cem Sinanoğlu $\mathbb{D}^{1},{ }^{1}$ and Emel Kizilkaya Aydoğan $\mathbb{D}^{2}$ \\ ${ }^{1}$ Department of Industrial Design Engineering, Faculty of Engineering, Erciyes University, Kayseri 38090, Turkey \\ ${ }^{2}$ Department of Industrial Engineering, Faculty of Engineering, Erciyes University, Kayseri 38090, Turkey \\ Correspondence should be addressed to Emel Kizilkaya Aydoğan; emelkizilkaya@gmail.com
}

Received 28 October 2019; Revised 2 April 2020; Accepted 16 April 2020; Published 12 May 2020

Academic Editor: Benjamin Ivorra

Copyright (c) 2020 Esra Akgül et al. This is an open access article distributed under the Creative Commons Attribution License, which permits unrestricted use, distribution, and reproduction in any medium, provided the original work is properly cited.

Companies need to develop new products towards customer's satisfaction in order to survive in the boom and bust cycle in todays' economy. The capturing of customer satisfaction depends on customer needs, and generally, understanding emotions has a challenge for designers. Kansei engineering is a type of methodology to help customers and designers analyze needs and emotion for the new product development. Producing new product design with Kansei data increases customer satisfaction and helps to reach market goals. In this study, a market-oriented baby cradle design methodology is proposed, and we obtain the new product strategies with association rule extraction by using rough set theory. To obtain efficient rules, beforehand we selected sales knowledge-related Kansei words with our proposed approach: cost-based and multiclass decision-theoretic rough set (DTRS) attribute reduction. The new product design strategies which are obtained with proposed design methodology are consistent with customer expectations (mood space) and expert opinions (design team).

\section{Introduction}

Today, all producers have technological advances in product development, and manufacturers have to catch customer expectations to achieve product satisfaction among the same product properties as in terms of performance, functional features, and price. The customers have difficulty to choose products with the same characteristics and different brands. The success of product design depends on understanding the needs of consumers. Today, product designers are searching effective approaches for catching customer satisfaction. They aim to increase to merchandisable of the product with catching emotion in this way.

Kansei engineering is a kind of methodology which is transformed from customer needs to design elements for pleasure from the product [1]. This method was founded by Mitsuo Nagamachi at Hiroshima University for customer satisfaction [2]. In this method, researchers or designers use different words such as adjectives, adverbs, and vocabularies related to senses to achieve their goals: catching customer needs and increase product satisfaction. These words are known as Kansei words that are the easiest way of accessing consumer's feel in the Kansei engineering methodology [3].
To analyze the Kansei data, multivariate statistical analysis such as partial least square, basic statistic, factor analysis, and artificial neural network is used for creating the new products $[2,4,5,6]$. At the same time, to find the relationships between Kansei and product feature sets, multiple linear regression analysis, neural networks, genetic algorithm, and rough set analysis are used as the most common methods [7].

Data mining that is the process of sorting through large amounts of data to extract relevant information is used to find related knowledge discovery in databases. In recent years, data mining approaches for Kansei-based product design are applied especially in the mobile phone [7], furniture [8], digital camera [9], truck cab [10], and toddler shoe [11] sector based on data. Shi et al. presented nonlinear data mining methods in Kansei engineering for mobile phone design [12]. Fung et al. developed a rule-mining method with a multiobjective genetic algorithm (GA) approach for affective product design to discover consumer perception of different design patterns and refine them to become a rule set to estimate emotional design [7]. Lokman et al. investigated Natphoric algorithm using in data classification and clustering to process Kansei words [13]. 
Sakornsathien et al. studied the application of data mining technique combining with Kansei engineering technique to predict possible design elements of a product which is appropriate for users [14].

On the contrary, rough set theory is able to deal with any kind of data and provides a framework of approximation and judgment about data [15-18]. This theory is an approach for judgment under uncertainty. It deals with imperfect information originating from the imprecision of human assessment. This mathematically powerful approach extracts knowledge from customer survey data and develops product design rules based upon single or multiple Kansei impressions from single or multiple users [19]. Nishino et al. found an extended rough set model for extracting decision rules from combined Kansei evaluation data and design attributes matched with customer Kansei for ball pen design. This method has been found to be useful for Kansei product design [20]. Zhai et al. used a rough set-based approach to extract reasonable Kansei knowledge from raw design information and to handle various design data involving nonlinearity, imprecision, and uncertainty [21]. Li et al. proposed an improved version of the strength Pareto evolutionary algorithm (SPEA2) for extraction of design knowledge by using multiobjective optimisation and rough sets for a car profile design. They claimed that the proposed systematic approach is suitable to effectively extract design knowledge for product form design [22]. Feng et al. suggested data-driven product design to make right decision with using data mining methods for designers and to predict customer requirement [23].

Furniture refers to moveable objects, such as beds, chairs, and tables, which are placed in a home or a workplace to make them suitable for living or working in [24]. Furniture industry is one of the most important design-intensive product groups all over the world market and has developed rapidly with new technologies. Every year, different kinds of wooden products are produced for bedroom, kitchen, chair, baby case, and so on [25]. In this study, we proposed a market-oriented product design methodology to obtain the new product strategies with association rule extraction by using rough set theory. To obtain efficient rules, cost-based multiclass decision-theoretic rough set (MCDTRS) attribute reduction algorithm with DTRS that is a kind of rough set theory is utilized to translate efficiently Kansei of customers into product characteristics in a furniture sector. In Section 2, the problem is defined in detail. The proposed algorithm is discussed in Section 3. In Section 4, the proposed approach is implemented in baby cradle design. As far as we know, no studies have about Kansei engineering and baby cradle with taking into account the cost-effectiveness in the literature. The existing research into new product demand is based on conventional statistical models that do not capture the changeable behavior of customer demand and market factors in manufacturing environments. This study can help designers to explore the shared design parameters of specific customer Kansei through a survey with the proposed methodology and can also evaluate differences of user groups quantitatively and at a low cost. The results of implementation are demonstrated and discussed in Section 5. Section 6 includes the conclusions and future work.

\section{The Proposed Cost-Based MCDTRS Attribute Reduction}

This section describes the idea of defining associated rules between product parameters and customer requirements on a customer satisfaction which are modeled with cost-sensitive learning method and apriori algorithm.

DTRS can be considered as a kind of cost-sensitive learning method which includes cost functions. In the DTRS model, three-way decisions are made to achieve the minimum cost of Bayesian decisions, including acceptance, rejection, and deferment decisions. However, since the cost matrix in conventional cost-sensitive learning problems does not include the cost of deferment decisions, DTRS cannot be used directly to solve traditional cost-sensitive learning problems [26].

In this paper, we present a cost-based MCDTRS attribute reduction algorithm which can obtain the relevant cost for deferment decisions based on the $3 \times \mathrm{m} \times \mathrm{m}$ cost matrix. In this section, we present the proposed cost-based MCDTRS attribute reduction method, and it is based on Zhou's MCDTRS formulation [27].

Definition 1. A decision table is the following tuple:

$$
S=\left(U, A t=C \cup D,\left\{V_{a} \mid a \in A t\right\},\left\{I_{a} \mid a \in A t\right\}\right),
$$

where $U$ is a finite nonempty set of objects, At is a finite nonempty set of attributes, $C$ is a set of condition attributes describing the objects, and $D$ is a set of decision attributes that indicate the classes of objects. $V_{a}$ is a nonempty set of values of $a \in A t$, and $I_{a}: U \longrightarrow V_{a}$ is an information function that maps an object in $U$ to exactly one value in $V_{a}$.

In a decision table, an object $x$ is described by its equivalence class under a set of attributes $A \subseteq A t:[x]_{A}=\left\{y \in U \mid \forall a \in A\left(I_{a}(x)=I_{a}(y)\right)\right\}$.

Definition 2. Let a finite set of $m$ classes $\Omega=\left\{C_{1}, C_{2}, \ldots, C_{m}\right\}$ be given. By a three-way decision, we mean each class $C_{i}$ is associated with a set of three actions $A=\left\{a_{P i}, a_{B i}, a_{N i}\right\}$, where $a_{P i}, a_{B i}$, and $a_{N i}$ represent the three actions in deciding $x \in \operatorname{POS}\left(C_{i}\right), x \in$ $\operatorname{BND}\left(C_{i}\right)$, and $\in \operatorname{NEG}\left(C_{i}\right)$, respectively.

The loss function is given by a $3 \times \mathrm{m}$ matrix for each class $C_{i}$ (Table 1).

Definition 3. For an arbitrary class in $\Omega=\left\{C_{1}, C_{2}, \ldots, C_{m}\right\}$, $\lambda\left(a_{P i} \mid C_{j}\right)$ is defined as the loss incurred to accept an object $x$ as a member of $C_{i}$ when its real class is $C_{j}, \lambda\left(a_{N i} \mid C_{j}\right)$ is defined as the loss incurred for rejecting an object $x$ as a member of $C_{i}$ when its real class is $C_{j}$, and $\lambda\left(a_{B i} \mid C_{j}\right)$ is defined as the loss incurred for neither accepting nor rejecting an object $x$ as a member of $C_{i}$ when its real class is $C_{j}$. In Zhou' s approach, it considers the losses that arise to make different wrong decisions as follows: 
TABLE 1: The loss function as a $3 \times \mathrm{m}$ matrix.

\begin{tabular}{|c|c|c|c|c|c|c|}
\hline & $C_{1}$ & $\mathrm{C}_{2}$ & $\cdots$ & $C_{j}$ & $\cdots$ & $C_{m}$ \\
\hline$a_{p i}$ & $\lambda_{P 1}=\lambda\left(a_{P i} \mid C_{1}\right)$ & $\lambda_{P 2}=\lambda\left(a_{P i} \mid C_{2}\right)$ & $\cdots$ & $\lambda_{P j}=\lambda\left(a_{P i} \mid C_{j}\right)$ & $\cdots$ & $\lambda_{P m}=\lambda\left(a_{P i} \mid C_{m}\right)$ \\
\hline$a_{b i}$ & $\lambda_{B 1}=\lambda\left(a_{B i} \mid C_{1}\right)$ & $\lambda_{B 2}=\lambda\left(a_{B i} \mid C_{2}\right)$ & . & $\lambda_{B j}=\lambda\left(a_{B i} \mid C_{j}^{\prime}\right)$ & $\cdots$ & $\lambda_{B m}=\lambda\left(a_{B i} \mid C_{m}\right)$ \\
\hline$a_{n i}$ & $\lambda_{N 1}=\lambda\left(a_{N i} \mid C_{1}\right)$ & $\lambda_{N 2}=\lambda\left(a_{N i} \mid C_{2}\right)$ & $\cdots$ & $\lambda_{N j}=\lambda\left(a_{N i} \mid C_{j}\right)$ & $\cdots$ & $\lambda_{N m}=\lambda\left(a_{N i} \mid C_{m}\right)$ \\
\hline
\end{tabular}

$$
\begin{cases}\lambda_{P i}=\lambda\left(a_{P i} \mid C_{j}\right), & \text { for all for all } i \neq j, \\ \lambda_{B i}=\lambda\left(a_{B i} \mid C_{j}\right), & \text { for all for all } i \neq j, \\ \lambda_{N i}=\lambda\left(a_{N i} \mid C_{j}\right), & \text { for all for all } i \neq j .\end{cases}
$$

For the multiclass case, the expected losses for taking different actions for objects $x \in[x]$

$$
R\left(a_{P i} \mid[x]\right)=\sum_{j=1}^{m} \lambda\left(a_{P i} \mid C_{j}\right) \operatorname{Pr}\left(C_{j} \mid[x]\right), R\left(a_{B i} \mid[x]\right)=\sum_{j=1}^{m} \lambda\left(a_{B i} \mid C_{j}\right) \operatorname{Pr}\left(C_{j} \mid[x]\right), R\left(a_{N i} \mid[x]\right)=\sum_{j=1}^{m} \lambda\left(a_{N i} \mid C_{j}\right) \operatorname{Pr}\left(C_{j} \mid[x]\right) .
$$

The minimum-risk decision rule suggested by Bayesian decision procedure is

$$
\begin{aligned}
& (P) \text { if } R\left(a_{P i} \mid[x]\right) \leq R\left(a_{B i} \mid[x]\right) \text { and } R\left(a_{P i} \mid[x]\right) \leq R\left(a_{N i} \mid[x]\right) \text {, decide } x \in \operatorname{POS}\left(C_{i}\right) \text {, } \\
& (B) \text { if } R\left(a_{B i} \mid[x]\right) \leq R\left(a_{P i} \mid[x]\right) \text { and } R\left(a_{B i} \mid[x]\right) \leq R\left(a_{N i} \mid[x]\right) \text {, decide } x \in \operatorname{BND}\left(C_{i}\right) \text {, } \\
& (N) \text { if } R\left(a_{N i} \mid[x]\right) \leq R\left(a_{P i} \mid[x]\right) \text { and } R\left(a_{N i} \mid[x]\right) \leq R\left(a_{B i} \mid[x]\right) \text {, decide } x \in \operatorname{NEG}\left(C_{i}\right) \text {. }
\end{aligned}
$$

Remark 1. Consider a special loss function with the following: the loss caused to make a mistake is greater than the loss done to be correct, and between the loss made to make a deferment decision, then the following is obtained:

$$
\begin{aligned}
& (c 1) \lambda\left(a_{P i} \mid C_{j}\right) \leq \lambda\left(a_{B i} \mid C_{j}\right)<\lambda\left(a_{N i} \mid C_{j}\right), \\
& \lambda\left(a_{N i} \mid C_{j}\right) \leq \lambda\left(a_{B i} \mid C_{j}\right)<\lambda\left(a_{P i} \mid C_{j}\right), \quad \text { for all } j, j \neq i .
\end{aligned}
$$

That is, the loss of classifying an object $x$ belonging to $C_{i}$ into the positive region $\operatorname{POS}\left(C_{i}\right)$ is less than or equal to the loss of classifying $x$ into the boundary region $\operatorname{BND}\left(C_{i}\right)$, and both of these losses are strictly less than the loss of classifying $x$ into the negative region NEG $\left(C_{i}\right)$. The reverse order of losses is used for classifying an object not in $C_{i}$. Under condition $(c 1)$, decision rules $(P)-(\mathrm{N})$ can be simplified as follows.

The minimum-risk decision rules for multiclass decision-theoretic rough sets can be rewritten as

$(P)$ if $\operatorname{Pr}\left(C_{i} \mid[x]\right) \geq \alpha_{i}$ and $\operatorname{Pr}\left(C_{i} \mid[x]\right) \geq \gamma_{i}$, decide $x \in \operatorname{POS}\left(C_{i}\right)$,

(B) if $\operatorname{Pr}\left(C_{i} \mid[x]\right) \leq \alpha_{i}$ and $\operatorname{Pr}\left(C_{i} \mid[x]\right) \geq \beta_{i}$, decide $x \in \operatorname{BND}\left(C_{i}\right)$,

$(N)$ if $\operatorname{Pr}\left(C_{i} \mid[x]\right) \leq \beta_{i_{i}}$ and $\operatorname{Pr}\left(C_{i} \mid[x]\right) \leq \gamma_{i}$, decide $x \in \operatorname{NEG}\left(C_{i}\right)$. 
Introducing three parameters,

$$
\begin{gathered}
\alpha_{i}=\frac{\sum_{j=1, j \neq i}^{m} \operatorname{Pr}\left(C_{j} \mid[x]\right)\left(\lambda\left(a_{P i} \mid C_{j}\right)-\lambda\left(a_{B i} \mid C_{j}\right)\right)}{\left(\lambda\left(a_{B i} \mid C_{i}\right)-\lambda\left(a_{P i} \mid C_{i}\right)\right)}, \\
\beta_{i}=\frac{\sum_{j=1, j \neq i}^{m} \operatorname{Pr}\left(C_{j} \mid[x]\right)\left(\lambda\left(a_{B i} \mid C_{j}\right)-\lambda\left(a_{N i} \mid C_{j}\right)\right)}{\left(\lambda\left(a_{N i} \mid C_{i}\right) \leq \lambda\left(a_{B i} \mid C_{i}\right)\right)}, \\
\gamma_{i}=\frac{\sum_{j=1, j \neq i}^{m} \operatorname{Pr}\left(C_{j} \mid[x]\right)\left(\lambda\left(a_{P i} \mid C_{j}\right)-\lambda\left(a_{N i} \mid C_{j}\right)\right)}{\left(\lambda\left(a_{N i} \mid C_{i}\right) \leq \lambda\left(a_{P i} \mid C_{i}\right)\right)} .
\end{gathered}
$$

Remark 2. The conditions of rule $(B)$ suggest that we can impose the constraint $\alpha_{i}>\beta_{i}$ so that the boundary region may be nonempty. A sufficient condition is added to ensure $\alpha_{i}>\beta_{i}$ :

$$
\text { (c2) } \frac{\lambda\left(a_{N i} \mid C_{i}\right) \leq \lambda\left(a_{B i} \mid C_{i}\right)}{\lambda\left(a_{B i} \mid C_{j}\right) \leq \lambda\left(a_{N i} \mid C_{j}\right)}>\frac{\lambda\left(a_{B i} \mid C_{i}\right) \leq \lambda\left(a_{P i} \mid C_{i}\right)}{\lambda\left(a_{P i} \mid C_{j}\right) \leq \lambda\left(a_{B i} \mid C_{j}\right)} \text {. }
$$

Conditions ( $c 1)$ and ( $c 2)$ imply that $\alpha_{i}>\gamma_{i}>\beta_{i} \geq 0$. After tie-breaking, the following simplified rules are obtained:

$(P)$ if $\operatorname{Pr}\left(C_{i} \mid[x]\right) \geq \alpha_{i}$, decide $x \in \operatorname{POS}\left(C_{i}\right)$,

(B) if $\beta_{i}<\operatorname{Pr}\left(C_{i} \mid[x]\right)<\alpha_{i}$, decide $x \in \operatorname{BND}\left(C_{i}\right)$,

$(N)$ if $\operatorname{Pr}\left(C_{i} \mid[x]\right) \leq \beta_{i}$, decide $x \in \operatorname{NEG}\left(C_{i}\right)$.

Definition 4. From the rules $(P),(B)$, and $(N)$, the $\left(\alpha_{i}-\beta_{i}\right)$ probabilistic positive, negative, and boundary regions are given, respectively, by

$$
\begin{aligned}
& \operatorname{POS}_{\left(\alpha_{i}, \beta_{i}\right)}\left(C_{i}\right)=\left\{x \in U \mid \operatorname{Pr}\left(C_{i} \mid[x]\right) \geq \alpha_{i}\right\}, \\
& \operatorname{BND}_{\left(\alpha_{i}, \beta_{i}\right)}\left(C_{i}\right)=\left\{x \in U \mid \beta_{i}<\operatorname{Pr}\left(C_{i} \mid[x]\right)<\alpha_{i}\right\}, \\
& \operatorname{NEG}_{\left(\alpha_{i}, \beta_{i}\right)}\left(C_{i}\right)=\left\{x \in U \mid \operatorname{Pr}\left(C_{i} \mid[x]\right) \leq \beta_{i}\right\} .
\end{aligned}
$$

Definition 5. Let $\pi_{A}$ denote the partition induced by the set of attributes $A \subseteq A t$ and $\pi_{D}=\left\{D_{1}, D_{2}, \ldots, D_{m}\right\}$ denote the partition of the universe $U$ induced by the set of decision attributes $D$. The three regions of the partition $\pi_{D}$ based on $(\alpha, \beta)$ can be defined as

$$
\begin{aligned}
& \operatorname{NEG}_{(\alpha, \beta)}\left(\pi_{D} \mid \pi_{A}\right)=\bigcup_{1 \leq i \leq m}\left(x \in U \mid \operatorname{Pr}\left(C_{i} \mid[x]_{A}\right)<\beta_{i}\right), \\
& \operatorname{POS}_{(\alpha, \beta)}\left(\pi_{D} \mid \pi_{A}\right)=\bigcup_{1 \leq i \leq m}\left(x \in U \mid \operatorname{Pr}\left(C_{i} \mid[x]_{A}\right) \geq \alpha_{i}\right), \\
& \operatorname{BND}_{(\alpha, \beta)}\left(\pi_{D} \mid \pi_{A}\right)=\bigcup_{1 \leq i \leq m}\left(x \in U \mid \beta_{i}<\operatorname{Pr}\left(C_{i} \mid[x]_{A}\right)<\alpha_{i}\right) .
\end{aligned}
$$

Class $C_{i}$ represents an arbitrary class from a set of decision classes $\left\{C_{1}, C_{2}, \ldots, C_{m}\right\}$. Further research is needed on the probabilistic three regions of a classification and the associated rules. In general, it is necessary to consider the issue of rule conflict resolution in order to make effective acceptance, rejection, and abstaining decisions.

Zhao et al. discussed many other conditions related to cost functions [28]. Unlike the rules in classical rough set theory, all three rule types derived from three regions may be ambiguous. They represent error tolerance levels in wrong decision-making. By considering the special case, where $\lambda\left(a_{P i} \mid C_{i}\right)=\lambda\left(a_{N i} \mid C_{j}\right)=0$, where $i \neq j$, cost is assumed zero, and we defined the decision costs of all rules and the Bayesian expected cost of each rule for the multiclass dataset which has $3 \times \mathrm{m} \times \mathrm{m}$ loss function:

$$
\begin{aligned}
& \text { cost of positive rule for class } C_{i}: \sum_{j=1, i \neq j}^{m}\left(1-\operatorname{Pr}\left(C_{i} \mid[x]_{A}\right)\right) \cdot \lambda\left(a_{P i} \mid C_{j}\right), \\
& \text { cost of boundary rule for class } C_{i}: \operatorname{Pr}\left(C_{i} \mid[x]_{A}\right) \cdot \lambda\left(a_{B i} \mid C_{i}\right)+\sum_{j=1, i \neq j}^{m}\left(1-\operatorname{Pr}\left(C_{i} \mid[x]_{A}\right)\right) \cdot \lambda\left(a_{B i} \mid C_{j}\right), \\
& \text { cost of negative rule for class } C_{i}: \sum_{j=1, i \neq j}^{m} \operatorname{Pr}\left(C_{i} \mid[x]_{A}\right) \cdot \lambda\left(a_{N i} \mid C_{j}\right) .
\end{aligned}
$$

For a given decision table, the decision cost of the table can be expressed as

$$
\begin{aligned}
\operatorname{COST}= & \sum_{i=1}^{m} \sum_{p_{t} \geq \alpha_{i}} \sum_{j=1, i \neq j}^{m}\left(1-p_{t}\right) \cdot \lambda\left(a_{P i} \mid C_{j}\right)+\sum_{i=1}^{m} \sum_{\beta_{i}<p_{t}<\alpha_{i}} p_{t} \cdot \lambda\left(a_{B i} \mid C_{i}\right)+\sum_{i=1}^{m} \sum_{\beta_{i}<p_{t}<\alpha_{i}} \sum_{j=1, i \neq j}^{m}\left(1-p_{t}\right) \cdot \lambda\left(a_{B i} \mid C_{j}\right) \\
& +\sum_{i=1}^{m} \sum_{p_{t} \leq \beta_{i}} \sum_{j=1, i \neq j}^{m} p_{t} \cdot \lambda\left(a_{N i} \mid C_{j}\right) .
\end{aligned}
$$


where $p_{t}=p\left(\arg \max _{D_{i} \in \pi_{D}}\left\{\left|\left[x_{t}\right]_{A} \cap D_{i}\right| /\left|\left[x_{t}\right]_{A}\right|\right\} \mid\left[x_{t}\right]_{A}\right)$. In this expression, the cost of the whole table is composed of three types of cost: cost of the positive rules, cost of the boundary rules, and cost of the negative rules.

According to the Bayesian decision principle, it is better to obtain a smaller value of the cost after removing some attributes. Jia et al. represented the cost formula based on attribute set $A \subseteq C$ [29]. In this section, we propose a MCDTRS-based attribute reduction model on the basis of the Zhou MCDTRS formulation. Some remarks on this model definition are given. By reviewing the DTRS model, we find that Bayesian decision procedure deals with making decisions with minimum cost based on observed evidence.

A change of three regions after removing some attributes leads to a change of decision cost, and we can represent the cost with equation (13) as an example of the proposed costbased MCDTRS attribute reduction which is explained as follows.

Example: a simple decision table $\mathbf{S}=\left(\mathbf{U}, \mathbf{A t}=\mathbf{C} \cup \mathbf{D},\left\{\mathbf{V}_{\mathbf{a}} \mid \mathbf{a} \in \mathbf{A t}\right\},\left\{\mathbf{I}_{\mathbf{a}} \mid \mathbf{a} \in \mathbf{A t}\right\}\right)$ is shown in Table 2. In this table, there are 20 objects and 6 attributes with four types of classes $\left\{\mathbf{C}_{1}, \mathbf{C}_{2}, \mathbf{C}_{3}, \mathbf{C}_{4}\right\}$. Each class $C_{-} i$ is associated with three actions $\mathbf{A}=\left\{\mathbf{a}_{\mathbf{P}_{i}}, \mathbf{a}_{\mathbf{B}_{\mathbf{B}_{1}}}, \mathbf{a}_{\mathbf{N}_{\mathbf{i}}}\right\}$. The column represents a set of attributes $\left\{\mathbf{s}_{1}, \mathbf{s}_{2}, \mathbf{s}_{3}, \mathbf{s}_{4}, \mathbf{s}_{5}, \mathbf{s}_{6}\right\}$, and the row represents objects $\left\{\mathbf{p}_{1}, \mathbf{p}_{2}, \ldots, \mathbf{p}_{20}\right\}$. For simplicity, binary values are only used.

Table 3 gives the loss function, and based on equation (13), we can compute the pairs of thresholds $\left(\alpha_{1}, \beta_{1}\right)$ as

$$
\begin{aligned}
\alpha_{1} & =\frac{\operatorname{Pr}\left(C_{2} \mid[x]\right)\left(\lambda\left(a_{P 1} \mid C_{2}\right)-\lambda\left(a_{B 1} \mid C_{2}\right)\right)+\operatorname{Pr}\left(C_{3} \mid[x]\right)\left(\lambda\left(a_{P 1} \mid C_{3}\right)-\lambda\left(a_{B 1} \mid C_{3}\right)\right)+\operatorname{Pr}\left(C_{4} \mid[x]\right)\left(\lambda\left(a_{P 1} \mid C_{4}\right)-\lambda\left(a_{B 1} \mid C_{4}\right)\right)}{\left(\lambda\left(a_{B 1} \mid C_{1}\right)-\lambda\left(a_{P 1} \mid C_{1}\right)\right)}, \\
& =\frac{0.2(4-2)+0.15(5-2)+0.25(12-6)}{10-0}=0.215 \\
\beta_{1} & =\frac{\operatorname{Pr}\left(C_{2} \mid[x]\right)\left(\lambda\left(a_{B 1} \mid C_{2}\right)-\lambda\left(a_{N 1} \mid C_{2}\right)\right)+r\left(C_{3} \mid[x]\right)\left(\lambda\left(a_{B 1} \mid C_{3}\right)-\lambda\left(a_{N 1} \mid C_{3}\right)\right)+r\left(C_{4} \mid[x]\right)\left(\lambda\left(a_{B 1} \mid C_{4}\right)-\lambda\left(a_{N 1} \mid C_{4}\right)\right)}{\left(\lambda\left(a_{N 1} \mid C_{1}\right)-\lambda\left(a_{B 1} \mid C_{1}\right)\right)}, \\
& =\frac{0.2(2-0)+0.15(2-0)+0.25(6-0)}{20-10}=0.20 .
\end{aligned}
$$

Similarly, we can get $\alpha_{2}=0.93, \beta_{2}=0.63 ; \alpha_{3}=0.90$, $\beta_{3}=0.81 ;$ and $\alpha_{4}=0.215, \beta_{4}=0.21$. For attribute subset $\left\{\mathbf{s}_{4}, \mathbf{s}_{5}\right\}$, we have regions and cost which are given in Table 4 .

According to the example, the cost of possible reducts is calculated, and the reduct $\left\{\mathbf{s}_{2}\right\}$ with minimum cost 79,74 is selected.

\section{The Apriori Algorithm}

The apriori is a kind of data mining algorithm which can be used to come up with the proper association rules for the generation of huge number of candidate sets as well as exploring all the possible combinations of the parameters [30]. Pseudo-code of the apriori is given in the following:

Pseudo-code:

$C_{k}$ : candidate item set of size $k$

$L_{k}$ : frequent item set of size $k$

$L_{1}=\{$ frequent items $\}$

for $\left(\mathbf{k}=1 ; \mathbf{L}_{\mathbf{k}} !=\varnothing ; \mathbf{k}++\right)$ do begin

$\mathbf{C}_{k+1}=$ candidates generated from $\mathbf{L}_{\mathbf{k}}$;

For each transaction $t$ in database do

Increment the count of all candidates in $\mathbf{C}_{\mathbf{k}+1}$ that are contained in $t$
$\mathbf{L}_{\mathbf{k}+1}=$ candidates in $\mathbf{C}_{\mathbf{k}+1}$ with min_support

end

return $\cup_{k} \mathbf{L}_{k}$;

lated by following equations:

$$
\operatorname{con}(\mathbf{A} \longrightarrow \mathrm{C})=\frac{\mathbf{T}(\mathbf{A} \& \mathbf{C})}{\mathrm{T}(\mathbf{A})},
$$

where $\mathrm{T}(\mathrm{A})$ is the number of cases in database T satisfying all the conditions in the antecedent $\mathrm{A}, \mathrm{T}(\mathrm{A} \& \mathrm{C})$ is the number of samples in database $T$ satisfying all the conditions in both antecedent $\mathrm{A}$ and the consequent $\mathrm{C}$, and $|\mathrm{T}|$ is the number of transactions.

$$
\sup (A \longrightarrow C)=\frac{T(A \& C)}{|T|}
$$

\section{The Proposed Market-Oriented Product Design Methodology}

The proposed methodology consists of 5 steps, and the flowchart of the proposed Kansei engineering model is given in Figure 1. 
TABle 2: A decision table.

\begin{tabular}{|c|c|c|c|c|c|c|c|c|c|c|c|c|c|c|c|c|c|c|c|c|c|}
\hline \multirow{2}{*}{\multicolumn{2}{|c|}{$s_{1}$}} & $p_{1}$ & $p_{2}$ & $p_{3}$ & $p_{4}$ & $p_{5}$ & $p_{6}$ & $p_{7}$ & $p_{8}$ & $p_{9}$ & $p_{10}$ & $p_{11}$ & $p_{12}$ & $p_{13}$ & $p_{14}$ & $p_{15}$ & $p_{16}$ & $p_{17}$ & $p_{18}$ & $p_{19}$ & $p_{20}$ \\
\hline \multirow{7}{*}{$S$} & & 1 & 1 & 0 & 1 & 1 & 0 & 1 & 1 & 1 & 0 & 1 & 1 & 0 & 1 & 1 & 1 & 0 & 1 & 1 & 0 \\
\hline & $s_{2}$ & 1 & 0 & 0 & 1 & 0 & 0 & 0 & 1 & 0 & 0 & 1 & 0 & 0 & 0 & 1 & 0 & 0 & 1 & 0 & 0 \\
\hline & $s_{3}$ & 1 & 1 & 1 & 1 & 1 & 0 & 1 & 1 & 1 & 1 & 1 & 1 & 0 & 1 & 1 & 1 & 1 & 1 & 1 & 0 \\
\hline & $s_{4}$ & 1 & 0 & 1 & 0 & 0 & 1 & 0 & 1 & 0 & 1 & 0 & 0 & 1 & 0 & 1 & 0 & 1 & 0 & 0 & 1 \\
\hline & $s_{5}$ & 1 & 1 & 0 & 0 & 1 & 1 & 1 & 1 & 1 & 0 & 0 & 1 & 1 & 1 & 1 & 1 & 0 & 0 & 1 & 1 \\
\hline & $s_{6}$ & 1 & 1 & 0 & 1 & 1 & 0 & 1 & 1 & 1 & 0 & 1 & 1 & 0 & 1 & 1 & 1 & 0 & 1 & 1 & 0 \\
\hline & & $c_{1}$ & $c_{2}$ & $c_{3}$ & $c_{4}$ & $c_{1}$ & $c_{2}$ & $c_{3}$ & $c_{4}$ & $c_{1}$ & $c_{2}$ & $c_{3}$ & $c_{4}$ & $c_{1}$ & $c_{2}$ & $c_{4}$ & $c_{1}$ & $c_{2}$ & $c_{1}$ & $c_{1}$ & $c_{1}$ \\
\hline
\end{tabular}

TABle 3: A loss function.

\begin{tabular}{ccccccccccccc}
\hline & $a_{P 1}$ & $a_{B 1}$ & $a_{N 1}$ & $a_{P 2}$ & $a_{B 2}$ & $a_{N 2}$ & $a_{P 3}$ & $a_{B 3}$ & $a_{N 3}$ & $a_{P 4}$ & $a_{B 4}$ & $a_{N 4}$ \\
\hline$c_{1}$ & 0 & 10 & 20 & 20 & 8 & 0 & 50 & 25 & 0 & 20 & 12 \\
$c_{2}$ & 4 & 2 & 0 & 0 & 13 & 32 & 53 & 23 & 0 & 14 & 4 \\
$c_{3}$ & 5 & 2 & 0 & 40 & 18 & 0 & 0 & 29 & 55 & 8 & 3 \\
$c_{4}$ & 12 & 6 & 0 & 50 & 30 & 0 & 70 & 27 & 0 & 0 & 30 & 60 \\
\hline
\end{tabular}

TABLE 4: The cost of attribute reduct $\left\{\mathbf{s}_{4}, \mathbf{s}_{5}\right\}$.

\begin{tabular}{|c|c|c|c|}
\hline Class & Objects & Region & Cost \\
\hline \multirow[t]{2}{*}{$C_{1}$} & $\begin{array}{c}o_{1}, o_{6}, o_{8}, o_{15} \\
o_{2}, o_{5}, o_{7}, o_{9}, o_{11}, o_{12}, o_{14}, o_{16}, o_{18}, o_{19} \\
o_{3}, o_{10}, o_{13}, o_{17}, o_{20}\end{array}$ & $\operatorname{POS}\left(C_{1}\right)$ & $\operatorname{POS}_{\left(\alpha_{1}, \beta_{1}\right)}\left(\pi_{D} \mid \pi_{\left\{s_{4}, s_{5}\right\}}\right)=15,75+10,5+12,6=38,85$ \\
\hline & $o_{4}$ & $\operatorname{NEG}\left(C_{1}\right)$ & $\mathrm{NEG}_{\left(\alpha_{1}, \beta_{1}\right)}\left(\pi_{D} \mid \pi_{\left\{s_{4}, s_{5}\right\}}\right)=0$ \\
\hline$C_{2}$ & $\begin{array}{c}o_{1}, o_{6}, o_{8}, o_{15} \\
o_{2}, o_{5}, o_{7}, o_{9}, o_{11}, o_{12}, o_{14}, o_{16}, o_{18}, o_{19} \\
o_{3}, o_{10}, o_{13}, o_{17}, o_{20} \\
o_{4}\end{array}$ & $\operatorname{NEG}\left(C_{2}\right)$ & $\operatorname{NEG}_{\left(\alpha_{2}, \beta_{2}\right)}\left(\pi_{D} \mid \pi_{\left\{s_{4}, s_{5}\right\}}\right)=8+6,4+12,8+0=27,2$ \\
\hline$C_{3}$ & $\begin{array}{c}o_{1}, o_{6}, o_{8}, o_{15} \\
o_{2}, o_{5}, o_{7}, o_{9}, o_{11}, o_{12}, o_{14}, o_{16}, o_{18}, o_{19} \\
o_{3}, o_{10}, o_{13}, o_{17}, o_{20} \\
o_{4}\end{array}$ & $\operatorname{NEG}\left(C_{3}\right)$ & $\operatorname{NEG}_{\left(\alpha_{3}, \beta_{3}\right)}\left(\pi_{D} \mid \pi_{\left\{s_{4}, s_{5}\right\}}\right)=0+11+11+0=22$ \\
\hline \multirow{2}{*}{$C_{4}$} & $\begin{array}{c}o_{1}, o_{6}, o_{8}, o_{15} \\
o_{4}\end{array}$ & $\operatorname{POS}\left(C_{4}\right)$ & $\operatorname{POS}_{\left(\alpha_{4}, \beta_{4}\right)}\left(\pi_{D} \mid \pi_{\left\{s_{4}, s_{5}\right\}}\right)=21+0=21$ \\
\hline & $\begin{array}{c}o_{2}, o_{5}, o_{7}, o_{9}, o_{11}, o_{12}, o_{14}, o_{16}, o_{18}, o_{19} \\
o_{3}, o_{10}, o_{13}, o_{17}, o_{20}\end{array}$ & $\operatorname{NEG}\left(C_{4}\right)$ & $\mathrm{NEG}_{\left(\alpha_{4}, \beta_{4}\right)}\left(\pi_{D} \mid \pi_{\left\{s_{4}, s_{5}\right\}}\right)=6+0=6$ \\
\hline $\operatorname{CosT}_{\left\{s_{4}, s_{5}\right\}}$ & 115,05 & & \\
\hline
\end{tabular}

4.1. Step 1: Identifying Target Groups. Firstly, the product samples are collected from the market. The target user is determined as parents, young parent candidates of future, academicians, and designers. The sales rate in the market is investigated for the product of design positioning.

4.2. Step 2: Span the Semantic Space for Evaluation. To identify a semantic space, different sources such as magazines, articles, interviews with users, websites of product companies, marketing personnel of companies, and product catalogs are investigated, and the adjectives are determined.

4.3. Step 3: Span the Space of the Product. The design parameters of the product are determined from market samples. Then, the different alternatives of product designs are composed of design elements for new product design with the morphological table.

4.4. Step 4: Synthesis. In this step, the product samples are evaluated with a questionnaire that is prepared with semantic differential (SD) scale. The SD scale that is a kind of the multipoint rating method was used for questionnaire [31].

The traditional preprocessing methods such as data cleaning, transformation of attributes, and data partitioning are applied to the data obtained from the questionnaire. After the preprocessing, cost-based MCDTRS algorithm is applied to obtain Kansei reduct. Then apriori algorithm is used to extract association rules between the Kansei words and design parameters. 


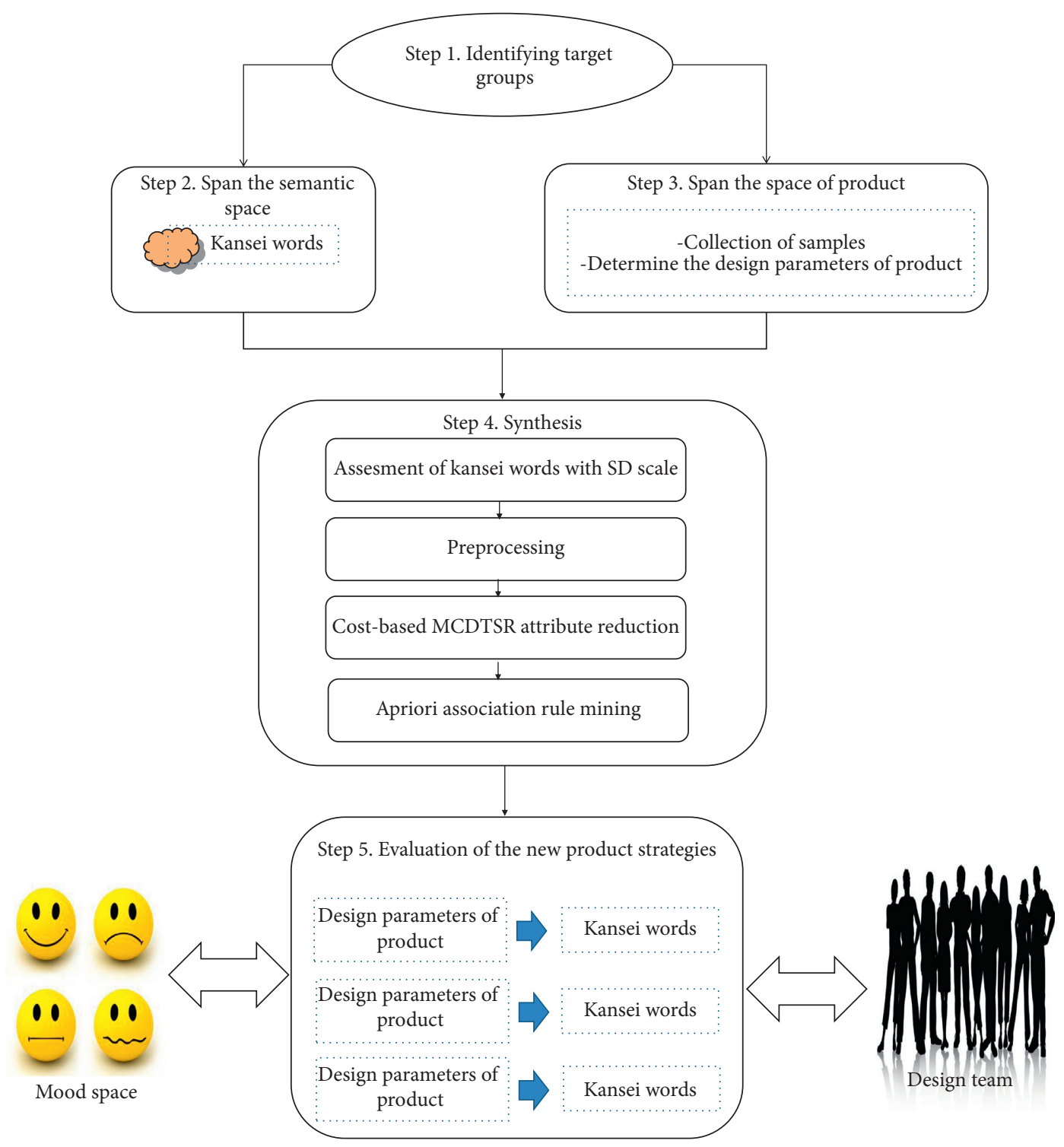

Figure 1: The flowchart of the proposed rough Kansei model.

4.5. Step 5: Evaluation of the New Product Strategies. In the consideration of the obtained rules which are regarding to different product parts and Kansei words, strategies for new product design are developed together with customer expectations and expert opinions.

4.6. Fitness Function Design. Fitness value is very important in evaluating the quality of each attribute subset, while obtaining Kansei reducts, decision cost (equation (13) designed as fitness function of the attribute reduction step. The fitness function of association rule mining algorithm apriori is designed as a measure which is based on both support and confidence. The purpose of this fitness function is to determine association rules, where both their support and confidence are greater than others. To achieve all valuable rules, high and low support and confidence fitness values are kept for further reference.
TABLE 5: The selected Kansei words.

\begin{tabular}{lc}
\hline Classic-modern & Feminine-masculine \\
\hline Simple-pompous & Cute-cheesy \\
Charmful-repellent & Funny-boring \\
\hline
\end{tabular}

\section{The Case Study: Baby Cradle}

To evaluate the proposed method, the case study of baby cradle design was conducted.

5.1. Step 1: Identifying Target Groups for the Baby Cradle. The baby cradle samples are collected from the market. The target user is determined as parents, young parent candidates of future, academicians, and designers. The sales rate in the market is investigated for the baby cradle of product design positioning. Later, the requirement of the product, 


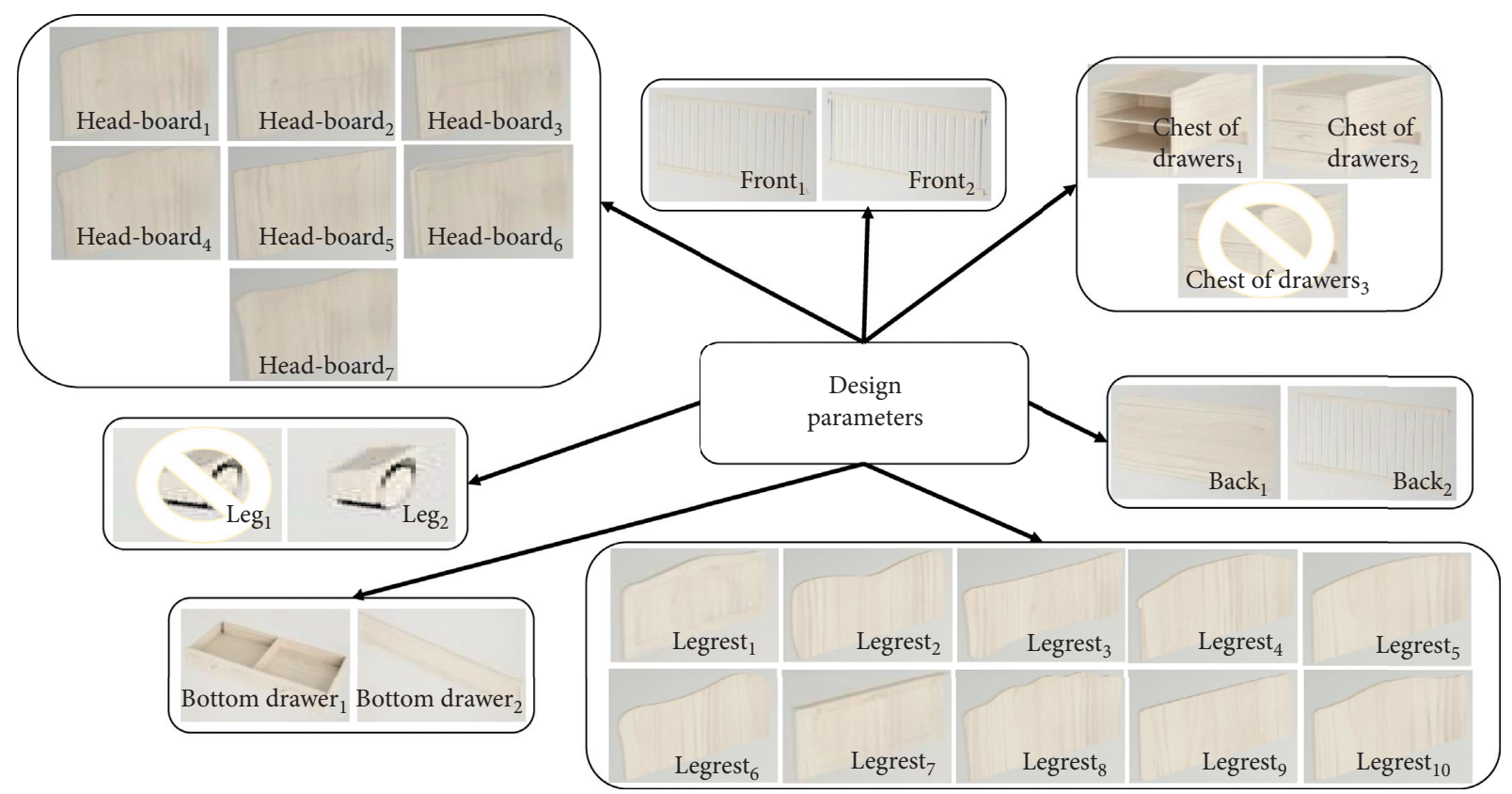

FIgURE 2: Design parameters of the baby cradle product.

the target user, and the market is determined for a baby cradle.

\subsection{Step 2: Span the Semantic Space for Baby Evaluation.} To identify a semantic space, different sources such as magazines, articles, interviews with users, websites of baby cradle companies, marketing personnel of companies, and product catalogs are investigated, and the adjectives are determined. Among the determined adjectives, the six pairwise Kansei words that describe the baby cradle were selected by a group composed of experts for use in this study to increase the reliability on the evaluation process. Table 5 shows the six Kansei adjectives that were most suitable for describing the baby cradle.

\subsection{Step 3: Determining the Design Parameters of the Baby} Cradle. The design parameters of the baby cradle are determined from market samples as seven different design parameters such as legrest, front block, chest of drawers, back, head board, bottom drawer, and leg. The different alternatives of baby cradle designs are composed of these design elements in this study. The design parameters of the baby cradle product are given in Figure 2.

5.4. Step 4: Synthesis. The SD scale is designed to use in a questionnaire with six pairwise Kansei data including classic-modern, feminine-masculine, simple-pompous, cute-cheesy, charmful-repellent, and funny-boring. The photos of baby cradle designs have been shown to participants. Each subject has evaluated each baby cradle design using an 11-point semantic scale. The photos of different baby cradle designs have been evaluated by 385 volunteer participants one by one. The time is limitless for the evaluation of this questionnaire.

Firstly, the questionnaire dataset is preprocessed, and then from the preprocessed dataset, the market-oriented Kansei word reduct is obtained with the proposed cost-based MCDTRS attribute reduction algorithm. The algorithm used the cost matrix in Table 6. The cost matrix was composed during the experiments to obtain the knowledge from the experts and company managers since it is not naturally equally important to classify the very low demand which will not start production and to classify that very high demand which will start production. Because the product is predicted as very low demand, unnecessary efforts will be made not to lose that customer, and when the baby cradle is estimated as very high demand, the not starting production will be lost if efforts are not made to keep the customer. The latter is much more important and costly than the former. The values given in the cost matrix indicate unit values and relative importance. For example, the product is designed and the manufacturer has three alternatives such as start to produce of product, make a prototype of the product and not start to produce of product for production. Starting produce of product brings extra cost such as technical drawing, mold etc. If the make prototype is prepared, the manufacturer has to wait and follow market demand. Finally, there is another choice for the manufacturer. This choice is not to start manufacturing this product. In a very high demand situation, if a product does not start to produce, the manufacturer sustains a loss. In the study of Shi et al. revealed that the RST-based reduct algorithm reduced the population scale appropriately with a smaller loss for product design. Our study supports previous different researchers' findings about validity of the method.

The cost-based MCDTRS algorithm is run with the cost matrix (as given in Table 7), and according to market expectations, four Kansei word pairs such as classic-modern, 
TABLE 6: Cost matrix of classifying the baby cradle.

\begin{tabular}{|c|c|c|c|c|c|c|}
\hline & & Very high demand & High demand & Midlevel demand & Low demand & Very low demand \\
\hline \multirow{3}{*}{ Very high demand } & Produce & 0 & 1 & 3 & 5 & 7 \\
\hline & Make prototype & 9 & 7 & 5 & 3 & 1 \\
\hline & Not produce & 10 & 8 & 6 & 4 & 2 \\
\hline \multirow{3}{*}{ High demand } & Produce & 2 & 0 & 4 & 6 & 8 \\
\hline & Make prototype & 8 & 6 & 4 & 2 & 1 \\
\hline & Not produce & 10 & 10 & 5 & 6 & 8 \\
\hline \multirow{3}{*}{ Midlevel demand } & Produce & 8 & 6 & 0 & 5 & 3 \\
\hline & Make prototype & 9 & 7 & 5 & 3 & 1 \\
\hline & Not produce & 10 & 9 & 7 & 5 & 3 \\
\hline \multirow{3}{*}{ Low demand } & Produce & 9 & 7 & 5 & 0 & 1 \\
\hline & Make prototype & 8 & 6 & 4 & 2 & 1 \\
\hline & Not produce & 10 & 9 & 8 & 3 & 1 \\
\hline \multirow{3}{*}{ Very low demand } & Produce & 9 & 8 & 6 & 4 & 0 \\
\hline & Make prototype & 5 & 4 & 3 & 2 & 1 \\
\hline & Not produce & 10 & 9 & 8 & 3 & 1 \\
\hline
\end{tabular}

TABLE 7: The obtained different association rules.

\begin{tabular}{|c|c|c|c|c|}
\hline \multicolumn{3}{|c|}{ Association rules } & \multirow{2}{*}{ Support } & \multirow{2}{*}{ Confidence } \\
\hline Design parameters & & Kansei adjectives & & \\
\hline Chest of drawers ${ }_{1}$ & $\Rightarrow$ & Modern & 0,2328 & 0,4430 \\
\hline Legrest $_{10}$ & $\Rightarrow$ & Feminine & 0,0559 & 0,4003 \\
\hline Chest of drawers $2 \Lambda$ bottom drawer ${ }_{1}$ & $\Rightarrow$ & Modern & 0,2368 & 0,9223 \\
\hline Head-board & $\Rightarrow$ & Neither feminine $\Lambda$ nor masculine & 0,0442 & 0,5145 \\
\hline $\operatorname{Leg}_{2}$ & $\Rightarrow$ & Classic $\Lambda$ simple & 0,03835 & 0,2545 \\
\hline Legrest $_{3}$ & $\Rightarrow$ & Pompous $\Lambda$ charmful & 0,03489 & 0,5231 \\
\hline $\mathrm{Back}_{1}$ & $\Rightarrow$ & Pompous $\Lambda$ charmful & 0,375371 & 0,799573 \\
\hline Legrest $_{2}$ & $\Rightarrow$ & Pompous $\Lambda$ charmful $\Lambda$ feminine & 0,293307 & 0,824175 \\
\hline Head-board $_{1}$ & $\Rightarrow$ & Repellent $\Lambda$ charmful & 0,0377 & 0,2504 \\
\hline Front $_{1}$ & $\Rightarrow$ & Pompous & 0,1047 & 0,2434 \\
\hline Chest of drawers ${ }_{2} \Lambda$ legrest $_{2}$ & $\Rightarrow$ & Classic $\Lambda$ feminine & 0,0344 & 0,4699 \\
\hline Legrest $_{8}$ & $\Rightarrow$ & Pompous $\Lambda$ charmful $\Lambda$ feminine & 0,129444 & 0,761576 \\
\hline Head-board 4 & $\Rightarrow$ & Charmful & 0,240356 & 0,736632 \\
\hline Bottom drawer 2 & $\Rightarrow$ & Classic $\Lambda$ charmful & 0,1196 & 0,4650 \\
\hline Head-board 6 & $\Rightarrow$ & Repellent $\Lambda$ classic & 0,142896 & 0,669326 \\
\hline
\end{tabular}

TABLE 8: Evaluated baby cradle design association rule set.

\begin{tabular}{|c|c|c|c|c|}
\hline \multicolumn{3}{|c|}{ Association rules } & \multirow{2}{*}{ Support } & \multirow{2}{*}{ Confidence } \\
\hline Design parameters & & Kansei adjectives & & \\
\hline Chest of drawers 1 $\Lambda$ bottom drawer $_{2}$ & $\Rightarrow$ & Modern & 0,2368 & 0,9223 \\
\hline Back $_{1}$ & $\Rightarrow$ & Pompous $\Lambda$ charmful & 0,375371 & 0,799573 \\
\hline Legrest $_{2}$ & $\Rightarrow$ & Pompous $\Lambda$ charmful $\Lambda$ feminine & 0,293307 & 0,824175 \\
\hline Legrest $_{8}$ & $\Rightarrow$ & Pompous $\Lambda$ charmful $\Lambda$ feminine & 0,129444 & 0,761576 \\
\hline Head-board 4 & $\Rightarrow$ & Charmful & 0,240356 & 0,736632 \\
\hline Head-board $_{6}$ & $\Rightarrow$ & Repellent $\Lambda$ classic & 0,142896 & 0,669326 \\
\hline
\end{tabular}

feminine-masculine, simple-pompous, and charmful-repellent have been reduced among the Kansei words that are given in Table 5. In the preprocessed questionnaire data, the rules from the data containing the reduced Kansei words were obtained by using the apriori algorithm.
5.5. Step 5: Evaluation Results of the New Baby Cradle Design Strategies. The rules that were obtained in the previous step are listed in Table 8 with the highest support and confidence values taking into account customer expectations and expert opinions. According to the results of Kansei rule mining, 


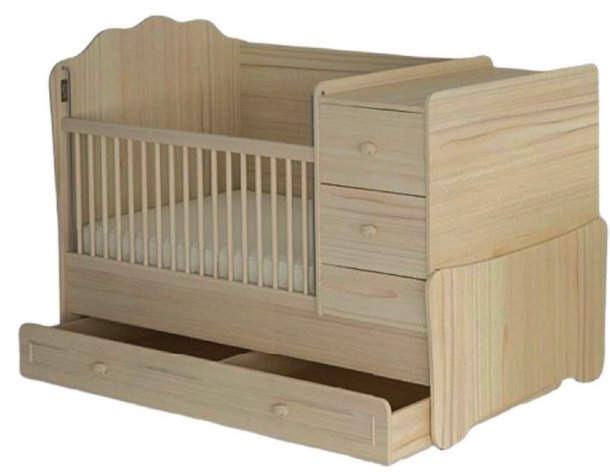

Figure 3: The sample of the baby cradle.

customers focus on the legrest, chest of drawer, bottom drawer, and head-board of parameters of the baby cradle.

The sample of the product with different parameters of the baby cradle for different Kansei words such as modern, pompous, and charmful is shown in Figure 3.

\section{Conclusions}

The manufacturers have to focus on effective market-oriented strategies to extract customers' needs and preferences and should use these strategies as the resource for new product design. Therefore, the furniture industry should pay more attention to consumer feelings for new product development and to data analysis for necessary factors of production and design.

This study contributes to the importance of relation between design and emotion knowledge by developing an algorithm for new product development in a fast-cycle furniture industry. Customer emotional knowledge towards design elements of the baby cradle was extracted using data mining techniques. The sets of rules were produced that could offer ideas and suggestions for new product development. The designers and producers can predict new product parameters thereby investigate customer behavior for salability in future research. Despite the fact that this study is related to the furniture industry as the baby cradle, the suggested methodology can be applied to other industries and different types of products. The findings of this study can be developed with fuzzy rules, metaheuristics, and so on.

\section{Data Availability}

The data used to support the findings of this study have not been made available. Because we have made the data security protocol with Çilek furniture firm, we cannot share the data. However, we confirm that our data and results are real.

\section{Conflicts of Interest}

The authors declare no conflicts of interest.

\section{Acknowledgments}

This work was supported by the Scientific and Technological Research Council of Turkey, “TÜBİTAK-TEYDEB” program with the project number-5170065. The authors would like to express their sincere thanks to the R\&D director Murat BULCA and to the entire group of development service at the Çilek Furniture.

\section{References}

[1] M. Nagamachi, "Kansei engineering as a powerful consumeroriented technology for product development," Applied Ergonomics, vol. 33, no. 3, pp. 289-294, 2002.

[2] S. Schütte and J. Eklund, "Design of rocker switches for workvehicles-an application of Kansei engineering," Applied Ergonomics, vol. 36, no. 5, pp. 557-567, 2005.

[3] H.-H. Lai, Y.-M. Chang, and H.-C. Chang, "A robust design approach for enhancing the feeling quality of a product: a car profile case study," International Journal of Industrial Ergonomics, vol. 35, no. 5, pp. 445-460, 2005.

[4] M. Nagamachi, "An image technology expert system and its application to design consultation," International Journal of Human-Computer Interaction, vol. 3, no. 3, pp. 267-279, 1991.

[5] T. Kanda, "Evaluation of human meal Kansei using AHP," in Proceedings of the 2005 IEEE Networking, Sensing and Control, pp. 431-436, Tucson, AZ, USA, March 2005.

[6] A. Ahmady, "Review and classification of kansei engineering and its applications," in Proceedings of the 4th Annual GRASP Symposium, Wichita State University, Wichita, Kansas, 2008.

[7] K. Y. Fung, C. K. Kwong, K. W. M. Siu, and K. M. Yu, "A multi-objective genetic algorithm approach to rule mining for affective product design," Expert Systems with Applications, vol. 39, no. 8, pp. 7411-7419, 2012.

[8] J. Pitaktiratham, T. Sinlan, P. Anuntavoranich, and S. Sinthupinyo, "Application of Kansei engineering and association rules mining in product design," International Journal of Social, Behavioral, Educational, Economic, Business and Industrial Engineering, vol. 6, no. 9, pp. 2352-2358, 2012.

[9] J. K. Bae and J. Kim, "Product development with data mining techniques: a case on design of digital camera," Expert Systems with Applications, vol. 38, no. 8, pp. 9274-9280, 2011.

[10] X. Yang, D. Wu, F. Zhou, and J. Jiao, "Association rule mining for affective product design," in Proceedings of the 2008 IEEE International Conference on Industrial Engineering and Engineering Management, Singapore, December 2008.

[11] M. Nagamachi, Y. Okazaki, and M. Ishikawa, "Kansei engineering and application of the rough sets model," Proceedings of the Institution of Mechanical Engineers, Part I: Journal of Systems and Control Engineering, vol. 220, no. 8, pp. 763-768, 2006.

[12] F. Shi, S. Sun, and J. Xu, "Employing rough sets and association rule mining in Kansei knowledge extraction," Information Sciences, vol. 196, pp. 118-128, 2012.

[13] A. M. Lokman, M. B. C. Haron, S. Z. Z. Abidin, and N. E. A. Khalid, "Natphoric kansei engineering systems (Nkes)," Journal of Telecommunication, Electronic and Computer Engineering, vol. 9, no. 2-3, pp. 77-81, 2017.

[14] K. Sakornsathien, S. Sinthupinyo, and P. Anuntavoranich, "Application of kansei engineering and data mining in developing an ingenious product Co-design system," International Journal of Machine Learning and Computing, vol. 9, no. 1, 2019.

[15] Z. a. Pawlak, "Rough sets," International Journal of Computer \& Information Sciences, vol. 11, no. 5, pp. 341-356, 1982.

[16] Z. Pawlak, Rough Sets-Theoretical Aspects of Reasoning about Data, Kluwer Academic Publishers, Dordrech, Netherlands, 1991. 
[17] Y. Kudo and T. Murai, "Semi-structured decision rules in object-oriented rough set models for Kansei engineering," in International Conference on Rough Sets and Knowledge Technology, pp. 219-227, Springer, Berlin, Heidelberg, 2007.

[18] A. Ahmady, Rough set kansei engineering: multiple users, multiple kansei, PhD thesis, Wichita State University, Wichita, Kansas, 2012.

[19] T. Nishino, M. Nagamachi, H. Okuo, and T. Itami, "Rough set model and its application to kansei engineering," in Proceedings of the 10th QMOD Conference. Quality Management and Organiqatinal Development. Our Dreams of Excellence, Linköping University Electronic Press, Helsingborg, Sweden, June 2007.

[20] T. Nishino, M. Nagamachi, and M. Sakawa, "Acquisition of kansei decision rules of coffee flavor using rough set method," Kansei Engineering International, vol. 5, no. 4, pp. 41-50, 2006b.

[21] L.-Y. Zhai, L.-P. Khoo, and Z.-W. Zhong, "A rough set based decision support approach to improving consumer affective satisfaction in product design," International Journal of Industrial Ergonomics, vol. 39, no. 2, pp. 295-302, 2009.

[22] Y. Li and L. Zhu, "Extracting knowledge for product form design by using multiobjective optimisation and rough sets," Journal of Advanced Mechanical Design, Systems, and Manufacturing, vol. 14, no. 1, 2020.

[23] Y. Feng, Y. Zhao, H. Zheng, Z. Li, and J. Tan, "Data-driven product design toward intelligent manufacturing: a review," International Journal of Advanced Robotic Systems, vol. 17, no. 2, 2020.

[24] Oxford Dictionary, 2019, http://www.oxfordlearnersdictionaries. com.

[25] C. M. Haines, The industrialization of wood: the transformation of a material, $\mathrm{PhD}$ thesis, University of Delaware, Newark, Delaware, 1990.

[26] X. Jia, W. Li, and L. Shang, "A multiphase cost-sensitive learning method based on the multiclass three-way decisiontheoretic rough set model," Information Sciences, vol. 485, pp. 248-262, 2019.

[27] B. Zhou, "Multi-class decision-theoretic rough sets," International Journal of Approximate Reasoning, vol. 55, no. 1, pp. 211-224, 2014.

[28] Y. Zhao, Sk M. Wong, and Y. Yao, "A note on attribute reduction in the decision-theoretic rough set model," in Transactions on Rough Sets XIII, pp. 260-275, Springer, Berlin, Heidelberg, 2011.

[29] X. Jia, W. Liao, Z. Tang, and L. Shang, "Minimum cost attribute reduction in decision-theoretic rough set models," Information Sciences, vol. 219, pp. 151-167, 2013.

[30] S. Harikumar and D. U. Dilipkumar, "Apriori algorithm for association rule mining in high dimensional data," in Proceedings of the International Conference on Data Sci Ence and Engineering, pp. 1-6, Cochin, India, August 2016.

[31] C. E. Osgood and G. J. Suci, The Measurement of Meaning, University of Illinois Press, Champaign, IL, USA, 1957. 